\title{
BIMBINGAN BELAJAR DI RUMAH MENGGUNAKAN ALAT PERAGA BLOK PECAHAN PADA MASA PANDEMI COVID 19
}

\author{
Sofia Sa' ${ }^{1^{*}}$, Agustina $\mathrm{Mei}^{2}$, Ningsih ${ }^{3}$, Maria Fatima $\mathrm{Mei}^{4}$, Maria Trisna Sero \\ Wondo $^{5}$, Stefania Baptis Seto ${ }^{6}$, Finsensius Yesekiel Naja ${ }^{7}$, \\ Konstantinus Denny Pareira Meke ${ }^{8}$, Grasela Sare Manda ${ }^{9}$ \\ 1,2,3,4,5,6,7,8,9 Universitas Flores, Ende, Indonesia \\ Penulis Koresponsensi: email: saosofia@gmail.com
}

\begin{abstract}
The impact of the COVID-19 pandemic is not only on the safety aspect of people's lives but also on the education aspect. One of the problems faced is that students have problems understanding each material given by the teacher because what has experienced so far is that students only get assignments online (What's App, E-Learning), then students do the assignments and send them back. At that moment, there is no direct explanation from the teacher, and each student's answer only relies on the internet (google), even though students need an understanding of the concepts in the material provided, especially mathematics for fractions. One of the activities that help students develop themselves in improving their learning abilities is the tutor. Solution offered to students who live in RT 003, Paupire Village, in this service activity is to provide Student learning assistance and guidance by using fractional block teaching aids during the Covid 19 Pandemic to increase understanding of concepts and learning outcomes. Tutoring can increase students' motivation and academic value, increase understanding of fraction concepts and learning outcomes.
\end{abstract}

\section{Keywords: work from home, Fractional block props}

\begin{abstract}
Abstrak. Dampak dari pandemi covid 19 bukan hanya pada aspek keselamatan hidup masayarakat, melainkan juga dirasakan pada aspek pendidikan. Salah satu permasalahan yang dihadapi ialah siswa memiliki kendala dalam pemahaman setiap materi yang diberikan oleh guru, karena yang dialami selama ini siswa-siswi hanya mendapatkan kiriman tugas melalui online (Whats App, E-Learning), lalu siswa mengerjakan tugas tersebut dan mengirim kembali tugas tersebut via online, tidak ada penjelasan langsung dari guru, dan setiap jawaban siswa hanya mengandalkan internet (google), padahal siswa butuh pemahaman konsep-konsep pada materi yang diberikan, terlebih khusus mata pelajaran matematika untuk materi pecahan. Salah satu kegiatan yang membantu peserta didik mengembangkan diri dalam meningkatkan kemampuan dalam pembelajaran ialah bimbingan belajar. Adapun solusi yang ditawarkan pada siwa-siswa yang berdomisili di RT 003, Kelurahan Pauipre tersebut dalam kegiatan pengabdian ini adalah dengan memberikan Pendampingan dan Bimbingan Belajar Siswa dengan menggunakan alat peraga blok pecahan dimasa Pandemi Covid 19 sampai pada peningkatan pemahaman konsepkonsep pecahan dan hasil belajar. Bimbingan belajar dapat meningkatkan motivasi belajar siswa dan nilai akademik, peningkatan pemahaman konsep-konsep pecahan dan hasil belajar.
\end{abstract}

Kata Kunci: Belajar dari rumah, Alat peraga blok pecahan

How to Cite: Sa'o, S.,Mei, A., Ningsih, N., Mei, M. F., Wondo, M. T. S., Seto, S. F., Naja, F. Y., Meke, K. D. P., \& Manda, G. S. (2021). Bimbingan Belajar di Rumah Menggunakan Alat Peraga Blok Pecahan pada Masa Pandemi Covid 19. Mitra Mahajana: Jurnal Pengabdian Masyarakat, 2(2), 193-201. https://doi.org/10.37478/mahajana.v2i2.1031

\section{PENDAHULUAN}

Kegiatan pembelajaran matematika dimasa pandemi Covid-19 membuat implementasinya cukup menyulitkan guru dan siswa. Salah satunya dikarenakan siswa yang diharuskan untuk belajar dari rumah. Jarak yang diakibatkan ini membuat orang tua mau tidak mau harus lebih aktif dalam memantau kegiatan anak di rumah selama sekolah diliburkan di Era Covid-19 ini (Khasanah, Pramudibyanto \& Widuroyekti, 2020).

Belajar dari Rumah (BDR) tetntu menuntut siswa harus dapat mengakses materi dan sumber pembelajaran tanpa batasan waktu dan tempat. Belajar dari Rumah (BDR) diharapkan dapat akan mendukung proses pembelajaran jarak jauh dan mempermudah dalam penyebaran materi kepada peserta didik (Kurniasari, Pribowo \& Putra, 2020). Di masa pandemi Covid-19, pembelajaran tentu harus tetap berlangsung agar perkembangan pengetahuan siswa tetap berjalan optimal. Tidak ada alasan untuk tidak dapat mengoptimalkan pembelajaran 
matematika bagi anak di masa Covid 19. Motivasi dari orang tua tentunya diperlukan untuk mendukung proses pembelajaran dari rumah. Namun dengan kesibukan orang tua, tentu hal ini menjadi tantangan tersendiri bagi keluarga dalam memberikan perhatian kepada pendidikan anak (Amalina, 2021: 546). Secara langsung orang tua harus turut berpartisipasi ketika sanga anak belajar dari rumah. Dampingan orang tua dirasa begitu dibutuhkan oleh anak untuk belajar/mengerjakan tugas sehingga dapat membantu anak dalam belajar (Hadiyanti \& Tyas, 2020: 441) (Darmayanti, dkk, 2020).

Pembelajaran yang menjadi perhatian lebih dari guru dan orang tua selama BDR salah satunya matematika. Pembelajaran matematika bagi siswa Sekolah Dasar sendiri hendaknya dibuat lebih menyenangkan dan objeknya dari hal sederhana yang dekat dan digemari anak (Amalina, 2021: 546). Siswa tingkat Sekolah Dasar belajar melalui aktivitas kerja, dimana siswa membutuhkan kerja dengan benda konkret sebagai media belajarnya (Sari, Jamaludin \& Hakim, 2021). Pembelajaran menggunakan alat peraga dalam pembelajaran matematika merupakan metode yang paling disarankan. Anak-anak dirasakan mengikuti pembelajaran dengan gembira, yang mengakibatkan siswa lebih yang membuat minta belajar mereka menjadi meningkat. Lebih lanjut sajian objek abstrak matematika pada alat peraga ,membuat siswa lebih memahami konsep dan teori yang dipelajari (Murdiyanto \& Mahatma, 2014:40). Pemahaman konsep merupakan pokok penting dalam proses pembelajaran matematika. Hal ini dikarenakan pemahaman konsep matematika merupakan landasan penting untuk menyelesaikan persoalanpersoalan dalam kehidupan sehari-hari (Kesumawati, 2016).

Siswa-siswa yang berdomisili di RT 003, Kelurahan Pauipre yang menjadi tempat kegiatan pengabdian masyarakat tengah dihadapi tantangan yang sama, di mana mereka dihatuskan belajar dari rumah dan paling dominan tengah mempelajari materi operasi pecahan. Maka, salah satu alat peraga yang di gunakan dalam pengabdian ini adalah alat peraga blok pecahan. Blok pecahan adalah sebuah media yang dibuat dari sebuah kertas lipat yang biasanya berbentuk persegi yang nantinya akan dibagi menjadi bagian-bagian kecil yang menunjukkan pecahan (Trisnawati, Suharno dan Kamsiyati, 2019).

Pembelajaran matematika dengan menggunakan alat peraga blok pecahan merupakan salah satu alternatif pembelajaran matematika dengan materi pecahan. Media blok pecahan memberikan pengaruh yang positif terhadap siswa (Seftyani, Hawa \& Usman, 2017:63). Blok pecahan merupakan alat peraga yang dapat diaplikasikan langsung oleh siswa sehingga membuat pembelajaran matematika menjadi lebih bermakna (Jumiati, Arjudin \& Rosyidah, 2020). Media blok pecahan membuat siswa dapat memahami konsep pecahan khususnya pada kemampuan berhitung pecahan Trisnawati, Suharno dan Kamsiyati, 2019).

\section{METODE PELAKSANAAN}

Bimbingan belajar dari rumah dilaksanakan di wilayah RT 003, Kelurahan Paupire, Kecamatan Ende Tengah, Kabupaten Ende. Kegiatan berlangsung disalah satu rumah warga di RT 003 tersebut yang mampu menampung sebanyak 40 siswa. Kegiatan dilaksanakan pada masa pandemi covid-19 sehingga tetap mematuhi protocol kesehatan. Siswa yang mengikuti bimbingan ini ialah siswa Sekolah Dasar yang mengalami kesulitan dalam pembelajaran matematika khususnya pada operasi bilangan pecahan. ( Santoso \& Rusmawati, 2019:39). Kegiatan ini dilaksanakan dibawah bimbingan 8 Dosen pendidikan matematika dan beberapa orang mahasiswa pendidikan matematika Universitas Flores yang membantu mengkondisikan jalannya kegiatan.

Fasilitas utama dalam pelaksanaan kegiatan ini ialah alat peraga blok pecahan untuk materi operasi hitung bilangan pecahan. Fasilitas penunjang dalam pelaksanaan kegiatan bimbingan belajar dari rumah ini adalah 1 rumah penduduk yang sesuai kriteria. Selain itu tim pembimbing juga menyediakan white board, alat tulis menulis, buku pelajaran siswa, makanan ringan (snack) dan permen sebagai reward (hadiah) untuk siswa. Kegiatan ini dilaksanakan selama bulan Januari hingga Juni 2021. Kegiatan selalu dilaksanakan pada hari Kamis pukul 15.00 WITA - 17.00 WITA di setiap minggu. 
Pelaksanaan kegiatan bimbingan belajar ini menggunakan enam tahapan, yaitu: (1) Memeriksa kelengkapan belajar siswa sekaligus mengatur dan mengajak siswa untuk mematuhi protocol kesehatan (2) ceramah/penjelasan materi termasuk menjelaskan fungsi dan kegunaan alat peraga, (3) demontrasi penggunaan alat peraga blok pecahan kepada siswa, (4) siswa diberikan kesempatan untuk mempraktekan penggunaan alat peraga sekaligus menemukan konsep operasi bilangan pecahan, (5) memberikan reward (hadiah) berupa alat tulis kepada siswa yang mampu menemukan konsep operasi bilangan pecahan , (6) Evaluasi

Metode pelaksanaan kegiatan ini secara deskriptif kualitatif. Teknik pengumpulan secara observasi untuk mengetahui perkembangan aktivitas dan peningkatan pemahaman konsep belajar siswa pada materi operasi bilangan pecahan, serta wawancara untuk mengetahui motivasi belajar siswa. Jenis data dalam penelitian ini tergolong data kualitatif. Teknik analisa data secara naratif deskriptif.

\section{HASIL DAN PEMBAHASAN}

Bedasarkan hasil wawancara dengan siswa-siswi dan orang tua yang berdomisili di RT 003 Keluarahan Paupire, mengungkapkan permasalahan yaitu siswa-siswi memiliki kendala dalam pemahaman setiap materi yang diberikan oleh Bapak/ibu guru, khususnya pelajaran matematika dalam pemahaman konsep pecahan serta operasi pecahan, karena yang dialami selama ini siswa-siswi hanya mendapatkan kiriman tugas melalui online (Whats App, ELearning), lalu siswa mengerjakan tugas tersebut dan mengirim kembali tugas tersebut via online, tidak ada penjelasan langsung dari guru, dan setiap jawaban siswa hanya mengandalkan internet (google), padahal siswa butuh pemahaman konsep-konsep pada materi yang diberikan.

Hal ini mengakibatkan siswa lebih memilih untuk mencari jawaban langsung dari internet mengenai soal tersebut. Selain itu terbatasnya ketersediaan buku dan sumber referensi juga seringkali membuat siswa mendapati sumber referensi yang salah (Muthy \& Pujiastuti, 2020: 101) (Megawanti, Megawati \& Nurkhafifah, 2020).
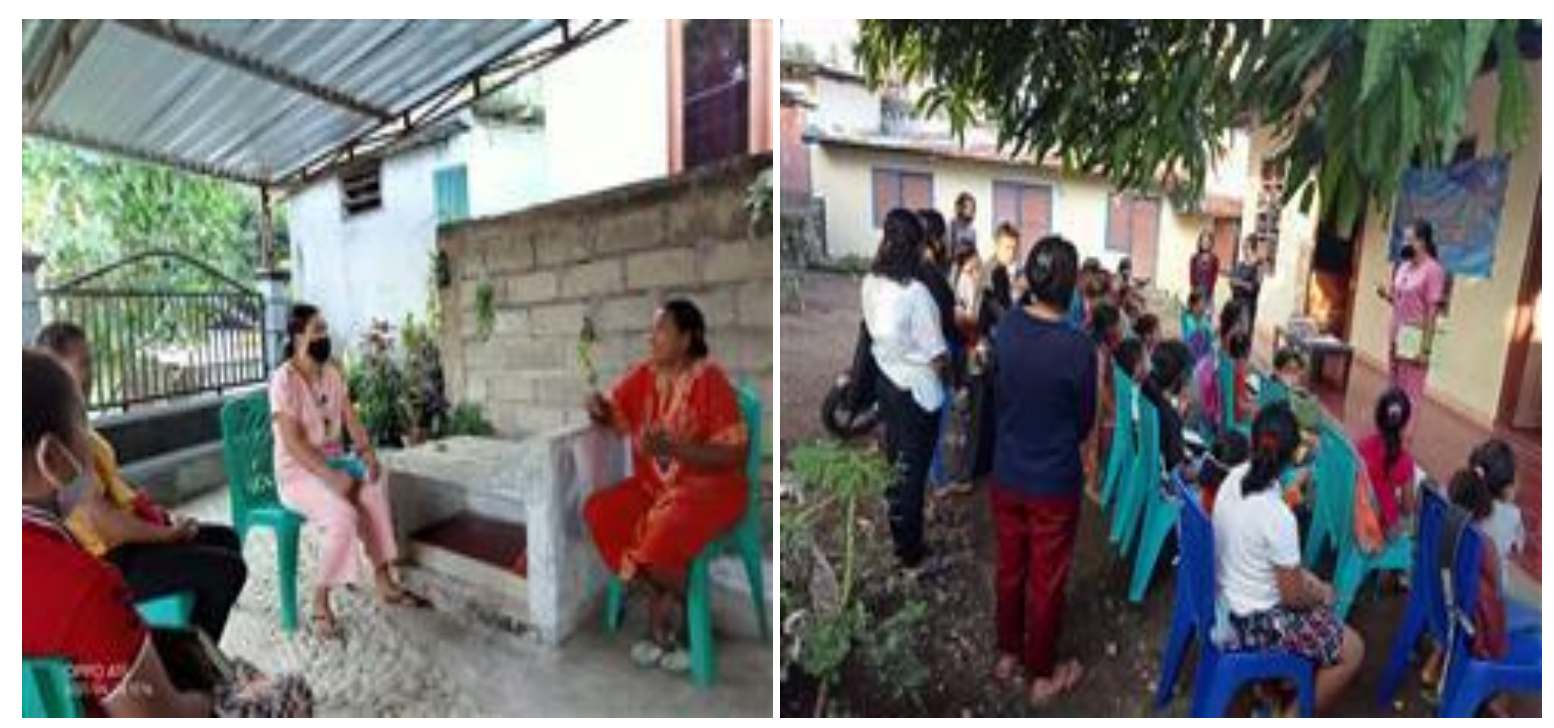

Gambar 1. Observasi dan wawancara dilakukan pada orang tua dan siswa-siswi

Lebih lanjut, penggunaan aplikasi e-learning yang baru dirasakan dan digunakan siswa membuat mereka tidak mampu belajar matematika secara maksimal (Yulia \& Putra, 2020:333). Dalam menciptakan suasana yang menarik dan kondusif terdapat beberapa faktor ekstrinsik atau faktor luar yang mempengaruhi pemahaman konsep matematika siswa seperti peran guru, dan lingkungan keluarga. Oleh karena itu, hal yang perlu diperhatikan oleh guru sebagai 
pendidik diantaranya yaitu komunikasi dalam pembelajaran dari rumah, materi yang dikemas secara menarik dan pengawasan siswa oleh guru sendiri

Solusi yang ditawarkan pada siwa-siswa yang berdomisili di RT 003 kelurahan Pauire tersebut dalam kegiatan pengabdian ini adalah dengan memberikan Pendampingan dan Bimbingan Belajar Siswa dengan menggunakan alat peraga blok pecahan. Blok pecahan dipilih sebagai media untuk mengajarkan konsep dan operasi pecahan (Fadillah, Susiaty \& Ardiawan, 2017: 5) (Mulyawati \& Kowiyah, 2018).

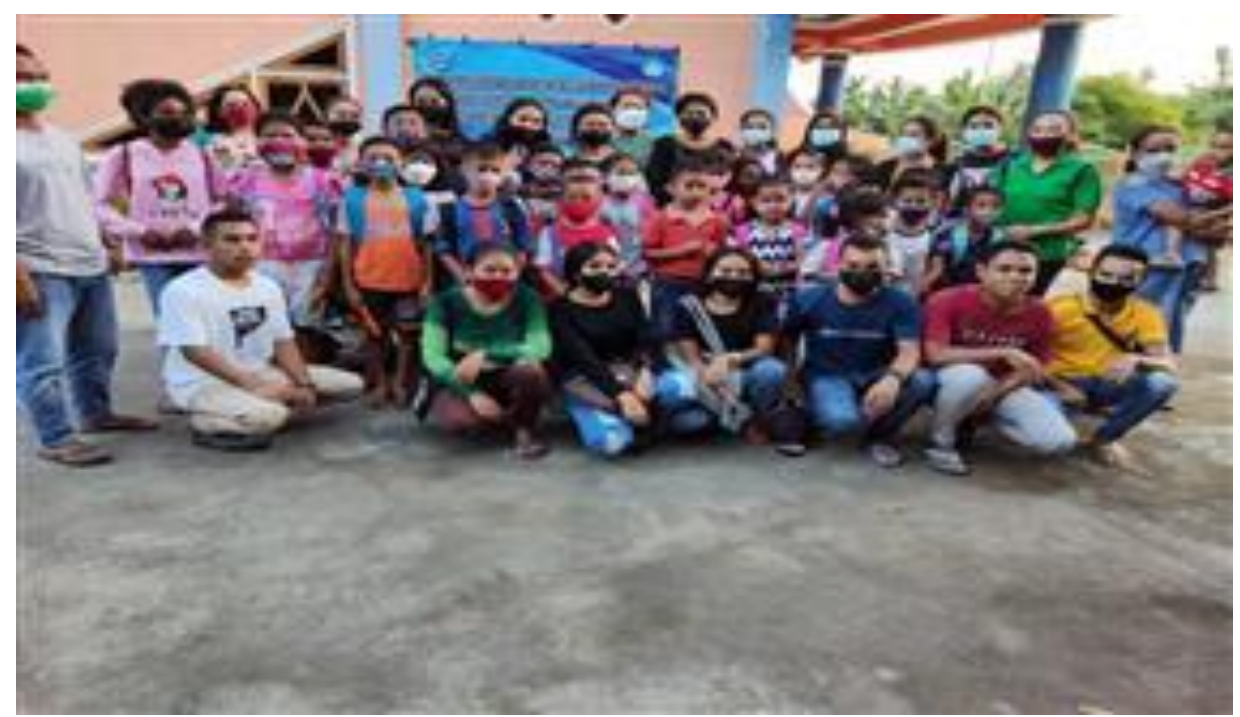

Gambar 2. Siswa-siswi komplek RT 003 Kelurahan Paupire, Ende bersama tim pengabdi

Secara umum kegiatan bimbingan dengan menggunakan alat peraga dalam mengoptimalkan pembelajaran dari rumah ini berlangsung sangat baik dengan menaati ptotokol kesehatan. Peserta terlihat semangat dan antusias, dalam melakukan bimbingan secara tatap muka. Banyak pertanyaan-pertanyaan dari siswa Sekolah Dasar menunjukan adanya respon positif dari mereka. Anak-anak sangat antusias dan bersemangat menjawab mengikuti bimbingan dan mengerjakan latihan yang diberikan oleh tim pengabdi (Isnurani, dkk 2021:124).

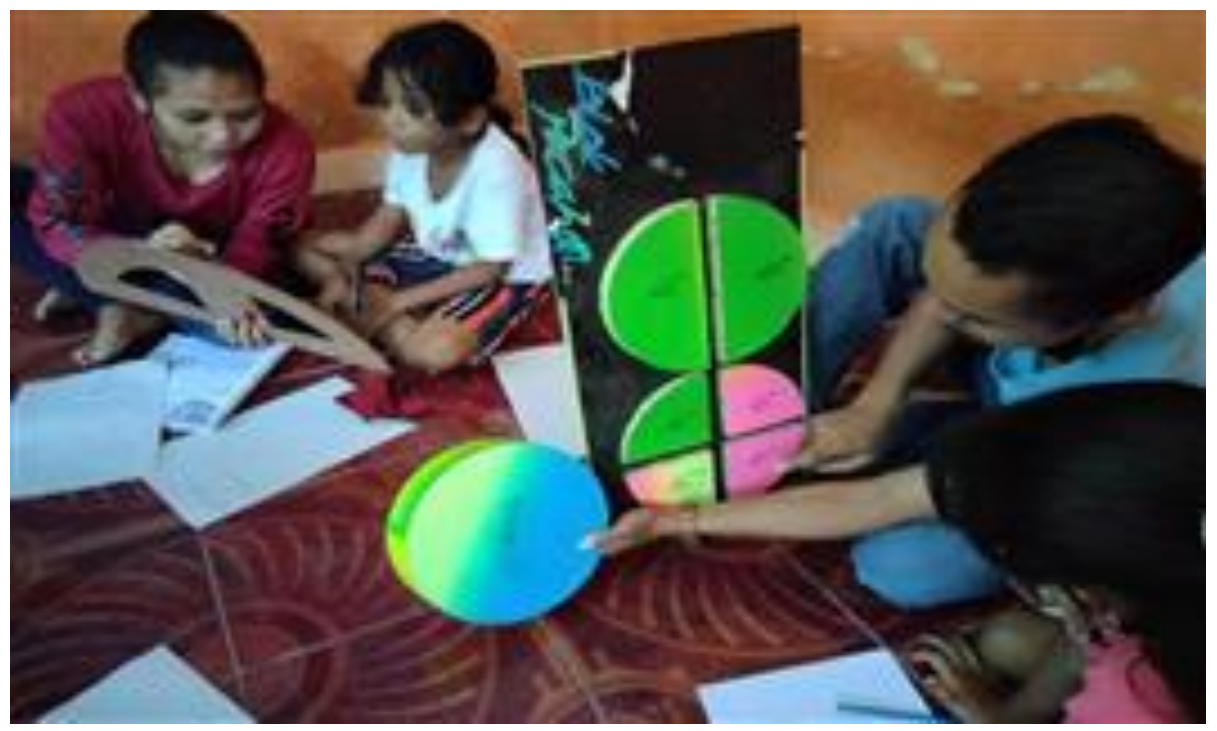

Gambar 3. Media blok pecahan 
Blok pecahan merupakan alat peraga yang berbentuk potongan-potongan blok atau lingkaran yang dibagi menjadi beberapa bagian. Ukuran dari blok pecahan dimulai dari 1, 1/2, 1/3 dan seterusnya(Nurhasanah, 2017:87). Penggunaan media blok pecahan diharapkan dapat menuntun siswa dalam memahami materi operasi pecahan karena siswa langsung menggunakan media dan menemukan sendiri konsep operasi hitung bilangan pecahan sehingga pemahaman siswa dapat menjadi kongkret. Selain itu, penggunaan media blok pecahan juga diharapkan dapat meningkatakan minta siswa dalam belajar dari rumah dan membuat proses bimbingan menjadi lebih menyenangkan (Indriani, 2018:15) (Latri, Syawaluddin \& Amrah, 2019:57).

Dalam kegiatan ini, kegiatan pertama yang dilakukan ialah membagi siswa menjadi beberapa kelompok kecil yang masing masing didampingi oleh mahasiswa secara langsung. Tahap ini bertujuan agar siswa lebih fokus dalam prosesnya dan pendampingan bertujuan mengarahkan siswa untuk dapat fokus menemukan konsep operasi pecahan (Octavia \& Purwanto, 2013: 5). Motivasi diberikan oleh dosen dan mahasiswa pendamping kepada siswa secara kelompok agar dalam proses bimbingan belajar dapat berlangsung kondusif dan dapat menumbuhkan kerjasama yang sehat dan aktif (Siswati, Margiati \& Kartono, 2016: 13). Siswa juga diharapkan mampu untuk dapat menyelesaikan latihan soal dan tugas yang diberikan pembimbing dengan melaksanakan kegiatan diskusi kelompok pada kelompok kecil yang telah dibagikan (Pujiati, Kanzunnudin \& Wanabuliandari, 2018:126).
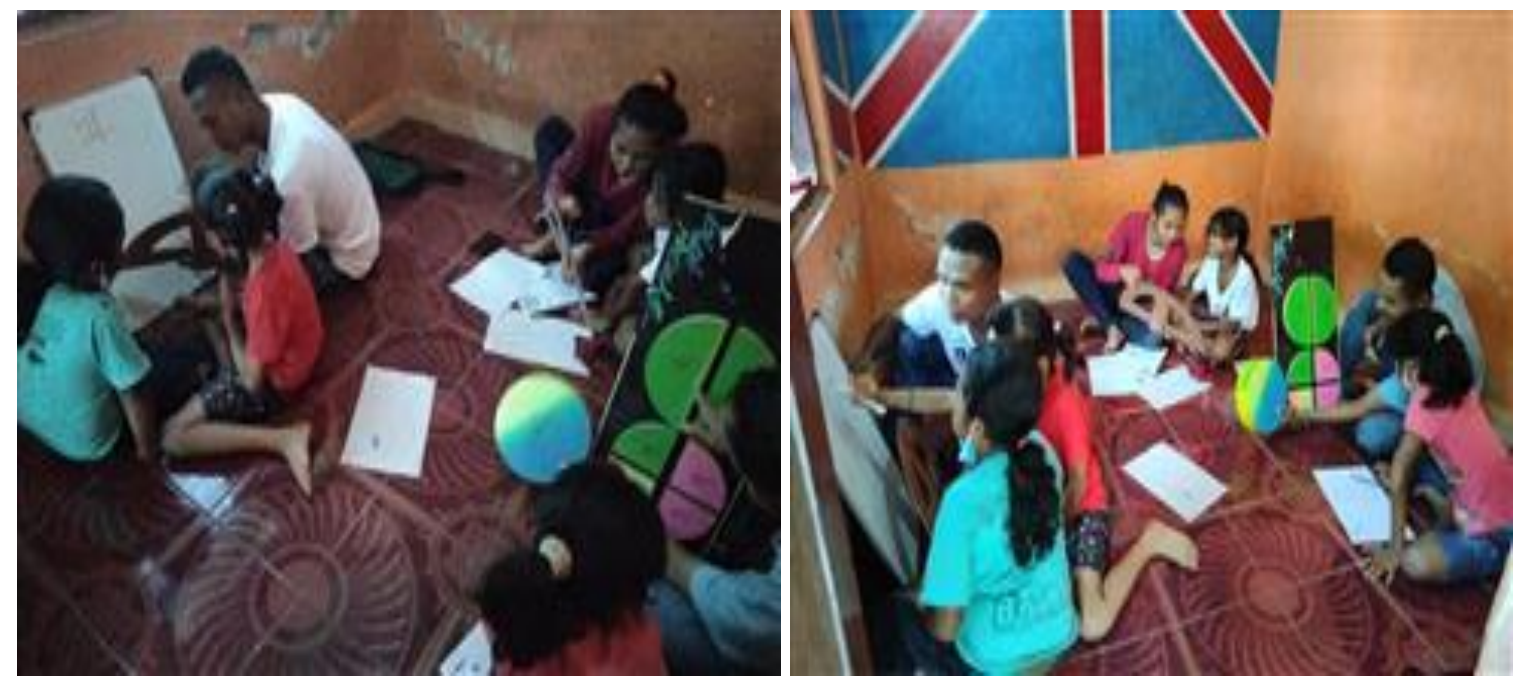

Gambar 4. Mahasiswa menjelaskan cara penggunaan media blok pecahan

Selanjutnya, setelah dibagi dalam kelompok kecil, mahasiswa dalam kelompok tersebut mulai menjelaskan fungsi dari alat peraga blok pecahan. Hal ini sebagai bentuk tanggung jawab pembimbing dalam membantu siswa menggunakan seuruh potensinya untuk mencapai aktualisasi yang maksimal (Sulistyorini, 2017:160). Bimbingan awal oleh mahasiswa ini juga bertujuan untuk lebih mengarahkan siswa agar menggunakan media dengan tepat dan menghindari kesalahn yang sering dilakukan sisiwa seperti tidak membaca petunjuk penggunaan dan operasi pecahan, serta kesalahan dalam perhitungan pecahan (Nuraini, Suhartono \& Yuniawatika, 2016:174). 


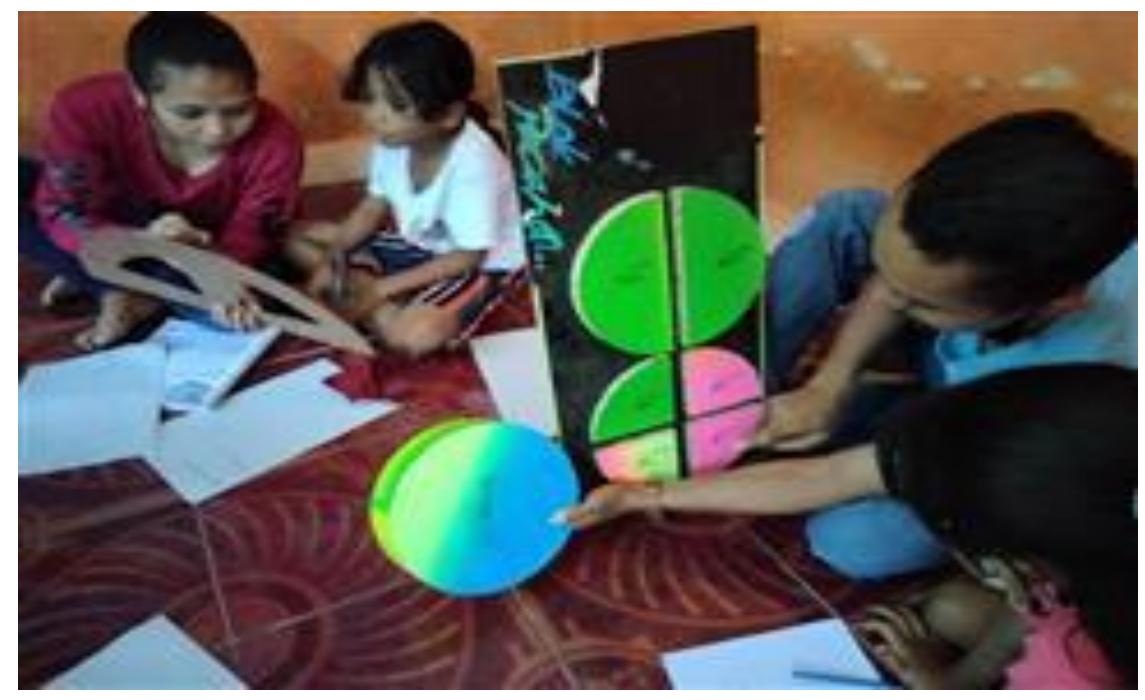

Gambar 5. Siswa menggunakan media blok pecahan dengan bimbingan mahasiswa

Setelah memahami bimbingan yang diberikan, siswa diminta secara konkrit Memeragakan alat peraga blok pecahan sembari menemukan konsep operasi bilangan pecahan dengan mengerjakan soal latihan yang diberikan. Tetap dalam bimbingan dosen dan mahasiswa, siswa terlihat sangat antusias dan aktif dalam proses pelaksanaannya. Dengan bimbingan dari tim meminta setiap siswa untuk menemukan konsep pecahan melalui alat peraga blok pecahan serta mengoperasikan bilangan pecahan (Yektyastuti, dkk. 2021:160). Susasana santai dan akrab namun tetap serius diciptakan agar siswa yang mengikuti kegiatan bimbingan lebih antusias dan semangat dalam mengikuti proses bimbingan. Penggunaan media blok pecahan juga membuat siswa semakin mudah memahami pembelajaran (Nasution, 2021:72).

Masa pandemi menjadi tantangan tersendiri bagi siswa Sekolah Dasar dalam proses pembelajaran. Bimbingan ini diharapkan mampu membantu siswa dalam proses pembelajaran di masa pademi seperti ini. Selain itu, keterlibatan mahasiswa secara langsung dalam proses bimbingan diharapkan dapat menyadarkan mereka sebagai penggerak pembangunan untuk terus belajar dan menerapkan ilmunya dalam kehidupan bermasyarakat. Mahasiswa diharapkan dapat menjadi contoh nyata, mampu untuk lebih kreatif, dan memotivasi siswa agar semangat dalam belajar dan meraih prestasi (Amrillah, dkk 2021).

\section{SIMPULAN DAN TINDAK LANJUT}

Melalui kegiatan pengabdian kepada masyarakat ini, diharapkan agar seluruh siswa-siswi mendapatkan ilmu pengetahuan yang tidak pernah mereka dapatkan pejelasan secara langsung dari guru-guru di sekolah tatap muka secara langsung dimasa pandemi covid-19, khususnya pemahaman konsep-konsep pecahan dan operasi pecahan dengan menggunakan alat peraga blok pecahan. Selain itu seluruh siswa-siswi mendapatkan pendampingan dan bimbingan secara langsung dalam mempergunakan alat peraga untuk operasi pecahan. Siswa-siswi RT 003 Kelurahan Paupire, Ende juga terlihat sangat antusias selama mengikuti bimbingan belajar, hal ini terlihat dari kehadiran dan respon baik dan aktif selama bimbingan belajar. Mereka terlihat aktif menggunakan alat peraga blok pecahan serta bersemangat dalam berdiskusi bersama kelompok kecilnya. Mereka tidak segan bertanya kepada mahasiswa yang membimbing mengenai materi yang belum mereka pahami. Pelaksanaan kegiatan pengabdian ini berjalan dengan baik dan lancar. 
Sofia Sa'o, Agustina Mei, Ningsih, Maria Fatima Mei, Maria Trisna Sero Wondo, Stefania Baptis Seto, Finsensius Yesekiel Naja, Konstantinus Denny Pareira Meke, Grasela Sare Manda

Mitra Mahajana: Jurnal Pengabdian Masyarakat 2(2), 2021, 193-201

\section{DAFTAR PUSTAKA}

Amalina, A. (2020). Pembelajaran Matematika Anak Usia Dini di Masa Pandemi Covid-19 Tahun 2020. Jurnal Obsesi : Jurnal Pendidikan Anak Usia Dini. 5(1), 538-548

Amrillah, M. A., dkk. (2021). BIMBINGAN BELAJAR DARI RUMAH DALAM MENINGKATKAN MINAT BELAJAR ANAK SEKOLAH DI DESA PACAR KECAMATAN TIRTO KABUPATEN PEKALONGAN. Kuliah Kerja Nyata Bersama Melawan Covid-19 Universitas Negeri Semarang, Kampus Sekaran Gunungpati Semarang. https://kkn.unnes.ac.id/lapkknunnes/32004_3326152010_6_Desa\%20Pacar_20201003 _004836.pdf. diakses tanggal 19 Juni 2021.

Darmayanti, N.W.S., dkk. (2020). PENDAMPINGAN BIMBINGAN BELAJAR DI RUMAH BAGI SISWA SD DUSUN BURUAN TAMPAKSIRING UNTUK MENUMBUHKAN MOTIVASI BELAJAR SISWA. SELAPARANG Jurnal Pengabdian Masyarakat Berkemajuan, 3(2), 207 210

Fadillah, S., Susiaty, U. D. \& Ardiawan, Y. (2017). PELATIHAN PENGGUNAAN MEDIA PEMBELAJARAN MATEMATIKA PADA SEKOLAH DASAR DI KECAMATAN PONTIANAK BARAT. GERVASI, Vol. 1, No. 1, 1-9

Hadiyanti, Y. R. \& Tyas, D. K. F. N. (2020). PEMBELAJARAN MATEMATIKA MENGGUNAKAN ALAT PERAGA KEPADA ORANG TUA MURID DALAM RANGKA MEMBANTU MENYELESAIKAN PEKERJAAN RUMAH. Jurnal Ilmiah Mandala Education. Vol. 6. No. 2. 441-448

Indriani, A. (2018). PENGGUNAAN BLOK PECAHAN PADA MATERI PECAHAN SEKOLAH DASAR Jurnal Ilmiah Pendidikan Matematika. Volume 3 Nomor 1, 11-16

Isnurani, I., Ilmadi, I., Aden, A., Sastro, G. ., Valentika, N., Nurbaiti, D., Sugianti, D., Ariffah, N., Lestari, P. I. ., Oktavian, S., Maesaroh, S., Nurmelani, V., N, V. V. ., \& Zufikar, P. (2021). Pelatihan Penggunaan Media Pembelajaran Matematika dalam Rangka Meningkatkan Motivasi Belajar Siswa Jurnal Abdidas, 2(1), 121-126. https://doi.org/10.31004/abdidas.v2i1.217

Jumiati, J., Arjudin, A., \& Rosyidah, A. N. K. (2020). PENGARUH PENGGUNAAN ALAT PERAGA BLOK PECAHAN TERHADAP HASIL BELAJAR MATEMATIKA SISWA KELAS III SDN 10 MATARAM. JURNAL ILMIAH PENDAS: PRIMARY EDUCATION JOURNAL, 1(1), 44-52. Retrieved from http://journal.unram.ac.id/index.php/pendas/article/view/54

Kesumawati, N. (2008). Pemahaman Konsep Matematik dalam Pembelajaran Matematika. Semnas Matematika dan Pendidikan Matematika. 229-235

Khasanah, D. R. A. U., Pramudibyanto, H., \& Widuroyekti, B. (2020). Pendidikan Dalam Masa Pandemi Covid-19.Jurnal Sinestesia, 10(1), 41-48. Retrieved from https://sinestesia.pustaka.my.id/journal/article/view/44

Kurniasari, A., Pribowo, F. S. P. \& Putra, D. A., (2020). ANALISIS EFEKTIVITAS PELAKSANAAN BELAJAR DARI RUMAH (BDR) SELAMA PANDEMI COVID-19. Jurnal Review Pendidikan Dasar: Jurnal Kajian Pendidikan dan Hasil Penelitian. 6(3), 246-235

Latri, L., Syawaluddin, A. \& Amrah, A. (2019). Pengaruh Penggunaan Media Blok Pecahan Terhadap Minat Belajar Pada Mata Pelajaran Matematika Siswa Kelas III SD Kompleks Lariang Bangi Kecamatan Makassar Kota Makassar. JIKAP PGSD: Jurnal Ilmiah Ilmu Kependidikan, Vol,3. No,1. 40-49

Megawanti, P., Megawati, E. \& Nurkhafifah, S. (2020). PERSEPSI PESERTA DIDIK TERHADAP PJJ PADA MASA PANDEMI COVID 19. Faktor Jurnal Ilmiah Kependidikan, Vol. 7 No. 2, hal 7582 
Sofia Sa'o, Agustina Mei, Ningsih, Maria Fatima Mei, Maria Trisna Sero Wondo, Stefania Baptis Seto, Finsensius Yesekiel Naja, Konstantinus Denny Pareira Meke, Grasela Sare Manda

Mitra Mahajana: Jurnal Pengabdian Masyarakat 2(2), 2021, 193-201

Mulyawati, I., \& Kowiyah, K. (2018). Pembelajaran Matematika dan IPA Guru SD Melalui Media $\begin{array}{lll}\text { Pembelajaran } & \text { Visual. Jurnal }\end{array}$ https://doi.org/10.29405/solma.v7i2.1652

Murdiyanto, T. \& Mahatma, Y. (2014). PENGEMBANGAN ALAT PERAGA MATEMATIKA UNTUK MENINGKATKAN MINAT DAN MOTIVASI BELAJAR MATEMATIKA SISWA SEKOLAH DASAR. Sarwahita: Jurnal Pengabdian Kepada Masyarakat. 11(1), 38-43

Muthy, A. N., \& Pujiastuti, H. (2020). Analisis media pembelajaran e-learning melalui pemanfaatan teknologi dalam pembelajaran matematika di rumah sebagai dampak 2019-nCoV. Jurnal Math Educator Nusantara: Wahana Publikasi Karya Tulis Ilmiah Di Bidang Pendidikan Matematika, 6(1), 94-103. https://doi.org/10.29407/jmen.v6i1.14356

Nasution, H. F. (2021). PENINGKATAN HASIL BELAJAR MATEMATIKA MELALUI BIMBINGAN BELAJAR GRATIS. Indonesian JournalOf Community Service. Volume 1 No 1, 66-73

Nuraini, N. L. S., Suhartono, S. \& Yuniawatika, Y. (2016). KESALAHAN SISWA PADA OPERASI PENJUMLAHAN DAN PENGURANGAN PECAHAN DI KELAS VI. SEKOLAH DASAR. Sekolah Dasar: Kajian Teori dan Praktik Pendidikan. 25 (2), hlm 168-175

Nurhasanah, A. (2017). UPAYA MENINGKATKAN KEMAMPUAN MENGENAL KONSEP PECAHAN MELALUI MEDIA BLOK PECAHAN PADA SISWA KELAS IV SDNEGERI CIDAHU 1 KECAMATAN DARMA KABUPATEN KUNINGAN JAWA BARAT. EDUCHILD, Vol. 6 No. 2, 86-90

Octavia, Y. \& Purwanto, P. (2013). PENGGUNAAN MEDIA BLOK PECAHAN DALAM MENINGKATKAN HASIL BELAJAR MATEMATIKA MATERI PENGURANGAN PECAHAN DI SEKOLAH DASAR. Jurnal Penelitian Pendidikan Guru Sekolah Dasar . 1(2), 1-10

Puspa, S., Riyono, J., \& Puspitasari, F. (2021). Analisis Faktor-Faktor yang Mempengaruhi Pemahaman Konsep Matematis Mahasiswa dalam Pembelajaran Jarak Jauh Pada Masa Pandemi Covid-19. Jurnal Cendekia : Jurnal Pendidikan Matematika, 5(1), 302-320. https://doi.org/10.31004/cendekia.v5i1.533

Pujiati, Kanzunnudin, M. \& Wanabuliandari, S. (2018). PENERAPAN CONTEXTUAL TEACHING AND LEARNING BERBANTU BLOK PECAHAN UNTUK PENINGKATAN PEMAHAMAN KONSEP SISWA. Anargya: Jurnal Pendidikan Matematika, Vol. 1 No.2, 122-129

Trisnawati, D. F., Suharno, S dan Kamsiyati, S. (2019). Efektivitas Media Realia dan Blok Pecahan Terhadap Kemampuan Berhitung Materi Pecahan Peserta Didik Sekolah Dasar. Jurnal Pendidikan Dasar. 7(1). 46-50

Santoso, A. \& Rusmawati, Y. (2019). PENDAMPINGAN BELAJAR SISWA DI RUMAH MELALUI KEGIATAN BIMBINGAN BELAJAR DI DESA GUCI KARANGGENENG LAMONGAN. Abdimas Berdaya: Jurnal Pengabdian Masyarakat Vol.2 No.2. 36-43

Sari, A. P., Jamaludin, J., \& Hakim, A. R. (2021). Pengembangan alat peraga BACALA (bangun datar, pecahan, labirin) untuk pembelajaran Matematika tingkat Sekolah Dasar. Himpunan: Jurnal Ilmiah Mahasiswa Pendidikan Matematika 1(1), 1-10.

Seftyani, Hawa, S. \& Usman, N (2017). PENGGUNAAN ALAT PERAGA BLOK PECAHAN PADA MATA PELAJARAN MATEMATIKA KELAS III DI SD NEGERI 11 INDRALAYA. JURNAL INOVASI SEKOLAH DASAR. 4(1), 57-63

Siswati, R., Margiati, K. Y. \& Kartono. (2016). PENINGKATAN HASIL BELAJAR PESERTA DIDIK MENGGUNAKAN MEDIA BLOK PECAHAN KELAS III SDN 21 PONTIANAK BARAT. JURNAL PENDIDIKAN DAN PEMBELAJARAN KHATULISTIWA. 5(5). 1-13 
Sofia Sa'o, Agustina Mei, Ningsih, Maria Fatima Mei, Maria Trisna Sero Wondo, Stefania Baptis Seto, Finsensius Yesekiel Naja, Konstantinus Denny Pareira Meke, Grasela Sare Manda

Mitra Mahajana: Jurnal Pengabdian Masyarakat 2(2), 2021, 193-201

Sulistyorini, S. (2017). MANAJEMEN PEMBELAJARAN MATEMATIKA MENGGUNAKAN ALAT PERAGA BLOK PECAHAN, LINGKARAN DAN KARTU PECAHAN. Manajer Pendidikan, Volume 11, Nomor 2, hlm. 160-164

Yektyastuti, R., dkk. (2021). Rumah Pintar : Bimbingan Belajar Siswa Sekolah Dasar di Masa Pandemi Covid-19. Educivilia: Jurnal Pengabdian pada Masyarakat. 2(1), 83-91. http://dx.doi.org/10.30997/ejpm.v2i1.3585

Yulia, I. B., Putra, A. (2020). Kesulitan Siswa Dalam Pembelajaran Matematika Secara Daring. Refleksi Pembelajaran Inovatif, $2(2)$, 327-335. https://doi.org/10.20885/rpi.vol2.iss2.art4 